\title{
Fetal role in the control of parturition in the tammar, Macropus eugenii
}

\author{
C. H. Tyndale-Biscoe, L. A. Hinds and C. A. Horn \\ Division of Wildlife and Ecology, CSIRO, P.O. Box 84, Lyneham, A.C.T. 2602, \\ Australia
}

\begin{abstract}
Summary. When female tammars carrying dormant blastocysts were injected with progesterone at the time of removal of their pouch young the development of the fetus was advanced and parturition occurred 5 days earlier than in the control tammars. In these tammars the prolactin pulse was also advanced by 5 days but the usually concomitant fall in progesterone was not. In non-pregnant tammars similar injections of progesterone did not advance the subsequent fall in progesterone, oestrus, or the LH pulse. In non-pregnant tammars injected with ovine prolactin on Day 26 , to mimic the prolactin pulse, plasma progesterone was reduced to basal levels within $12 \mathrm{~h}$, significantly earlier than in controls. Conversely, in 5 pregnant and 1 non-pregnant tammar injected with ovine prolactin on Day 23, to mimic the condition induced by advancing the time of parturition with progesterone, the decline in plasma progesterone was not advanced and the endogenous prolactin pulse, parturition, post-partum ovulation and the LH pulse all occurred after intervals similar to those of controls.

The results support the view that the fetus is associated with the pre-partum prolactin pulse in maternal plasma and that a prolactin pulse at this stage is luteolytic in non-pregnant tammars.
\end{abstract}

Keywords: tammar; fetus; parturition; prolactin

\section{Introduction}

Although it is well established that the fetus plays an important role in the timing and onset of parturition in eutherian mammals, it is only recently that a similar role has been suggested to occur in marsupials. Kirsch \& Poole (1972) and Poole (1975) observed that the gestation lengths of grey kangaroos, Macropus giganteus, carrying hybrid fetuses sired by males of $M$. fuliginosus were significantly shorter than normal, and intermediate between the gestation lengths of the two species. They suggested that the genotype of the fetus had influenced the length of gestation. In the tammar, $M$. eugenii, a different influence was ascribed to the fetus by Merchant (1979), who showed that the interval from oestrus to post-partum oestrus in this species was shorter than the interval from oestrus to the next oestrus in non-pregnant tammars. This was confirmed by Tyndale-Biscoe et al. (1983), who also showed that the profiles of several hormones were different between pregnant and non-pregnant cycles in the same group of tammars. Most notably, in the pregnant cycles a transient pulse of prolactin occurred less than $8 \mathrm{~h}$ before parturition on Day 26-27, coincident with a precipitate fall in plasma progesterone, whereas in the non-pregnant cycles there was no pulse of prolactin and the decline in progesterone was slower, taking 3 days longer to complete. It was suggested from this that the prolactin pulse is luteolytic at the end of pregnancy and that the fall in progesterone is the trigger for oestrus and the preovulatory pulse of $\mathrm{LH}$, which occur at fixed intervals after it. In three other studies the association of a prolactin pulse at parturition has also been observed. Hinds $\&$ Tyndale-Biscoe (1982b) observed a pulse in 2 pregnant females but in none of 4 non-pregnant 
females, while Hinds \& Tyndale-Biscoe (1985) observed a prolactin pulse associated with birth in $9 / 10$ females and in none of 3 non-pregnant females at oestrus. In another unpublished study by the same authors a pulse of prolactin was observed in 8/9 pregnant tammars and in 2/12 non-pregnant tammars. In total, therefore, a prolactin pulse at the end of the cycle has been observed in $26 / 28$ pregnant tammars and in $2 / 26$ non-pregnant tammars.

Lewis et al. (1986) have shown that there is a substantial but very short-lived peak of the metabolite of prostaglandin F-2 $\alpha$ (PGFM) between $20 \mathrm{~min}$ before and $1 \mathrm{~h}$ after parturition and in 5 out of 10 animals investigated the fall in progesterone occurred after the peak in PGFM. They conclude that prostaglandin, rather than prolactin, is the agent of luteolysis in the tammar, as it is in the marsupial Isoodon macrourus (Gemmell, 1985) and in eutherian species, and that the transient pulse of prolactin in pregnant tammars is involved in the onset of lactation. While prolactin has been shown to be the main or only hormone required to induce milk protein synthesis in tammar mammary tissue, maximal response is achieved with concentrations of prolactin equivalent to basal levels in circulation (Nicholas \& Tyndale-Biscoe, 1985). Similarly, in the unpublished study referred to above, the transfer of neonates to the pouches of non-pregnant females, which did not display a prolactin pulse at the end of the cycle, induced lactation. These observations do not support the contention that the pre-partum pulse of prolactin is necessary for lactogenesis and so leave open the question of its role in luteolysis.

Although the drop in progesterone is a very distinctive feature of peripartum events in the tammar, an experimental reduction of progesterone by excision of the corpus luteum on Day 23,3 days early, did not lead to premature parturition, premature oestrus or premature LH pulse (Harder et al., 1985), nor did extending the period of elevated progesterone with exogenous progesterone from Days 24 to 29 delay parturition or post-partum oestrus (Ward \& Renfree, 1984).

Two questions remain unresolved by these studies: (1) is the prolactin pulse induced by the fetus and is it involved in the timing of the events at parturition, and (2) is a prolactin pulse at the end of the reproductive cycle directly or indirectly luteolytic? To examine these questions we exploited a phenomenon described by Clark (1968) in the red kangaroo (Macropus rufus). During lactation, the red kangaro undergoes embryonic diapause, which, like in the tammar, can be terminated by removing the pouch young. By injecting kangaroos with progesterone for 3 days before removing the pouch young, Clark (1968) induced premature reactivation of the embryo and dissociated fetal development from the ovarian cycle, so that parturition occurred several days before oestrus. Likewise in the tammar, exogenous progesterone induces a more rapid reactivation of the blastocyst (Moore, 1978), with birth occurring on Day 23 (Renfree \& Tyndale-Biscoe, 1973), than reactivation induced by removing the pouch young, when birth occurs on Day 26-28 (Merchant, 1979). Therefore this difference in response could be used to test whether the prolactin pulse is associated with the fetus or the ovarian cycle and, if with the former, whether it induces premature luteolysis.

\section{Materials and Methods}

Animals. The tammars used in these experiments came from the breeding colony originally established in 1974 with stock from Kangaroo Island and subsequently maintained at the CSIRO Division of Wildlife and Ecology in Canberra. Six groups of 5 or 6 adult females in the first month of lactation after the start of the breeding season were selected for Exps 1 and 2 (Tables 1 and 2) and throughout the experiment each group was held in a separate open grassy pen provided with pelleted lucerne hay and oats and water ad libitum. The females in Groups 1-3 (Exp. 1) had associated with males at post-partum oestrus and each could be expected to be carrying a blastocyst in diapause, while the females in Groups 4-6 (Exp. 2) had been separated from males at this time and each would be carrying an unfertilized egg. Reactivation of the quiescent corpus luteum (CL) was induced in all 30 females by removing their pouch young on Day 0.

On Day 0 to Day 3 each animal received an intramuscular (i.m.) injection of $10 \mathrm{mg}$ progesterone (Calbiochem progesterone No. 5341) in olive oil (Drug Houses of Australia, BP pure virgin Tritest) (Groups 2 and 5) or olive oil alone (Groups 1, 3, 4 and 6). On Day 23 the animals in Group 1 were injected i.m. with $0.5 \mathrm{ml}$ saline and those in Group 3 with $200 \mu$ g ovine prolactin in $0.5 \mathrm{ml}$ saline. On Day 26 the animals in Group 4 were injected i.m. with $0.5 \mathrm{ml}$ saline and those in Group 6 with $200 \mu \mathrm{g}$ ovine prolactin in $0.5 \mathrm{ml}$ saline (Table 2). At the end of the experiments 
oestrus was detected from the presence of copulatory plugs in the urogenital sinus. For this reason two adult males were introduced to each pen on Day 18 and, from Day 22, all the pregnant animals were checked 3 times a day for birth and post-partum oestrus, and from Day 26 all the non-pregnant animals were checked 3 times a day for signs of aestrus. Those that had not given birth or shown oestrus by Day 32 were killed and examined for evidence of undetected oestrus and for ovulation.

Experimental design. The aim of Exp. 1 was to investigate the involvement of the fetus in the prolactin pulse and parturition. For this the animals in Group 2 received progesterone to induce development of the blastocyst in advance of the CL, with the expectation that parturition would occur on Day 23; the non-pregnant females of Group 5 received progesterone to demonstrate the lack of effect of progesterone treatment in the absence of the conceptus. Assuming that the tammars in Group 2 would give birth on Day 23 and show a prolactin pulse at this time, the pregnant tammars in Group 3 were injected with prolactin on Day 23 to mimic this and test whether it would induce a premature fall in progesterone and premature parturition.

The aim of Exp. 2 was to test for the luteolytic effect of the pre-partum prolactin pulse and its effect on the timing of oestrus and ovulation. To do this the non-pregnant tammars in Group 6 were injected with prolactin on Day 26, the day that a pulse has been shown to occur in pregnant tammars (Hinds \& Tyndale-Biscoe, 1982b, 1985; Tyndale-Biscoe et al., 1983).

Collection of blood samples. Blood samples $(2.5 \mathrm{ml})$ were taken from a lateral tail vein once a day from Day 0 to Day 10, then on Days 12, 16 and 19, and daily from Day 22 for progesterone. From Day 23 in the pregnant groups and from Day 26 in the non-pregnant groups until Day 29 blood samples $(3.5 \mathrm{ml})$ were taken at 8 -h intervals for progesterone and prolactin or LH assay. After the plasma had been separated the red blood cells were resuspended in sterile sodium citrate solution and returned to the tammar once a day. All plasma samples were stored at $-20^{\circ} \mathrm{C}$ until assayed.

Hormone assays. Hormone concentrations were determined by radioimmunoassays previously validated for the tammar. All samples of each hormone for one animal were measured in one assay.

Progesterone was assayed according to the method of Sernia et al. (1980) with progesterone antiserum S230, provided by Dr R. I. Cox (CSIRO, Sydney). The assay sensitivity was $25 \mathrm{pg} / \mathrm{ml} \mathrm{plasma,} \mathrm{and} \mathrm{intra-} \mathrm{and} \mathrm{interassay}$ coefficients of variation were $9 \%$ and $13 \%$ respectively.

Prolactin was determined with a heterologous radioimmunoassay, validated for the tammar by Hinds \& TyndaleBiscoe (1982b), using antibody 33-9, provided by Dr A. S. McNeilly, and ovine prolactin NIH-P-S12 as standard. The limit of sensitivity was $3 \mathrm{ng} / \mathrm{ml}$ plasma, and intra- and interassay coefficients of variation were $8 \%$ and $12 \%$ respectively. A pulse was defined as an elevation in concentration of more than twice the previous and subsequent levels.

LH was determined with a double-antibody heterologous radioimmunoassay validated for the tammar by Sutherland et al. (1980), using ovine antiserum GDN-15, provided by Dr G. D. Niswender and NIH-LH-S19 as standard. The assay sensitivity was $0.3 \mathrm{ng} / \mathrm{ml}$ and the intra- and interassay coefficients were $6 \%$ and $13 \%$ respectively.

Analysis of results. The results in Tables 1 and 2 were analysed separately and analysis of variance was used in each to assess significant differences amongst the three groups. Contrasts of particular interest are those between the control and each of the two experimental groups and these are summarized in Tables $I$ and 2 by contrast estimates of the mean differences and s.e.m. Wherever there were only two groups to compare the analysis of variance reduced to a 2-sample $t$ test. In Exp. 2 all females in Group 6 showed a fall in progesterone at the same time and, since there was consequently no variance about the mean, the Group was excluded from the analysis of variance, and to test whether the mean response in Group 4 was significantly different from that in Group 6 a 1 -sample $t$ test was used.

\section{Results}

\section{Experiment 1: fetal influence on prolactin pulse}

All pregnant tammars in control Group 1 showed a progesterone pulse before Day 12, indicating that reactivation had occurred after removal of the pouch young. The mean ( \pm s.e.m.) interval to the progesterone pulse was $7 \cdot 8 \pm 0.8$ days and to birth was $29.4 \pm 1.0$ days after removal of the pouch young (Table 1; Fig. 1a). The mean gestation period was unusually long but the interval of 21.6 days between the pulse and birth is the normal interval (Hinds \& Tyndale-Biscoe, 1982a), so the longer gestation intervals were due to the longer interval to the start of reactivation and not to a delay in parturition. The other events associated with parturition occurred in the normal sequence previously described for this species (Tyndale-Biscoe et al., 1983; Harder et al., 1985); 3 of the 5 animals had a brief pulse of prolactin and 5 had a rapid decline in progesterone, coincident with or preceding birth; all 5 displayed post-partum oestrus, 4 showed a brief preovulatory pulse of LH and all ovulated (Table 1; Fig. la). The prolactin pulse in 2 and the LH pulse in 1 tammar may have been missed because in these two animals only daily samples of blood were being taken by the time 
birth occurred on Day 31. The animals in this control group behaved normally in every respect except for a delay in reactivation. As the same conditions applied to all groups, direct comparison with Groups 2 and 3 can be made.

One of the 5 tammars of Group 2, treated with progesterone, was excluded from analysis; it was killed on Day 26 after the remaining animals had given birth, and was found to be in advanced pregnancy and parturition was judged to be imminent. During the first 4-5 days after removal of their pouch young plasma progesterone concentration was grossly elevated as a result of the injections on Days $0-3$, so that any endogenous early pulse of progesterone was undetectable (Fig. Ib). The 4 remaining animals gave birth between Day 22 and 26 , the mean interval being $24 \cdot 5 \pm 0.9$ days from removal of the pouch young and the start of progesterone injections, or $4.9 \pm 1.3$ days earlier than in the control Group $1(P<0.01$, Table 1). Each of these 4 animals had a marked pulse of prolactin at the same time as or $8 \mathrm{~h}$ before the young was detected in the pouch, i.e. $4.4 \pm 1.6$ days earlier than in the control Group $1(P<0.05$, Table 1). However, the fall in concentration of progesterone was not as closely associated with the prolactin pulse and birth as in Group 1 (Fig. $1 b)$; the concentration of progesterone remained elevated in the 2 animals that had a prolactin pulse and gave birth on Day 22 and Day 24 but declined immediately in the 2 that had a prolactin pulse and gave birth on Day 23 and Day 26. Only 2 came into oestrus and 2 had an LH pulse but these events were also earlier than in Group 1 (Table 1; Fig. 1b). The young born on Day 22 died within a day, whereas those born on Days 23-26 survived.

Of the 6 tammars in Group 3, treated with prolactin on Day 23, one was found at autopsy to be not pregnant and is excluded from comparison with Group 1 but will be compared with Group 6 : The remaining 5 pregnant tammars all gave birth and 3 showed oestrus and an LH pulse and, as in Group 1, the intervals were longer than in previous studies. The interval from the progesterone pulse to birth was $23.4 \pm 1 \cdot 2$ days, 2 days longer than normal, but none of the values measured differed significantly from those of Group 1 (Table 1). All 5 animals had a massive pulse of prolactin $4 \mathrm{~h}$ after the injection on Day 23 (Fig. 2c), as well as a subsequent smaller prolactin pulse, associated with parturition, and a fall in concentration of progesterone. The latter are not evident in Fig. 2(c) because they occurred at different times in each animal. In the first sample, taken $4 \mathrm{~h}$ after the prolactin injection, the concentration of progesterone in all 5 animals increased by $78 \%$ to $132 \%$ and 1 day later had reverted to the previous level. Therefore, the exogenous prolactin on Day 23 did not cause a decline in the concentration of progesterone, although the subsequent much smaller endogenous pulses were associated in each animal with parturition and the fall in progesterone. The same response to the injection of prolactin on Day 23 was seen in the one nonpregnant animal in Group 3, with an initial rise of $92 \%$ and then a reversion to normal elevated concentrations until Day 31 when progesterone declined to basal values.

\section{Experiment 2: luteolytic effects of prolactin}

The 5 non-pregnant animals in control Group 4 reactivated in response to the removal of their pouch young and displayed the progesterone pulse after an interval of $8.6 \pm 0.5$ days and 3 displayed oestrus after $31.6 \pm 0.4$ days (Table 2 ). The interval between the early progesterone pulse and the decline in progesterone was $21.8 \pm 0 \cdot 2$ days, the same as for Group 1, but, as with Group 1, the total duration of the cycle was longer than normal. In 4 animals an LH pulse was detected and in the fifth it was probably missed because of infrequent sampling at the appropriate time, since this animal was the last to reactivate and at autopsy on Day 32 it had a large preovulatory follicle, while the rest had already ovulated. These intervals and the associated profiles of progesterone, prolactin and $\mathrm{LH}$ are the same as those previously published for the end of the non-pregnant cycle in the tammar (Tyndale-Biscoe et al., 1983), except that one animal had a pulse of prolactin of $45 \mathrm{ng} / \mathrm{ml}$ on Day 29 coincident with the fall in progesterone and $32 \mathrm{~h}$ before the LH pulse. As mentioned in the 'Introduction', a prolactin pulse at this stage has previously only been observed in $2 / 26$ nonpregnant females. 


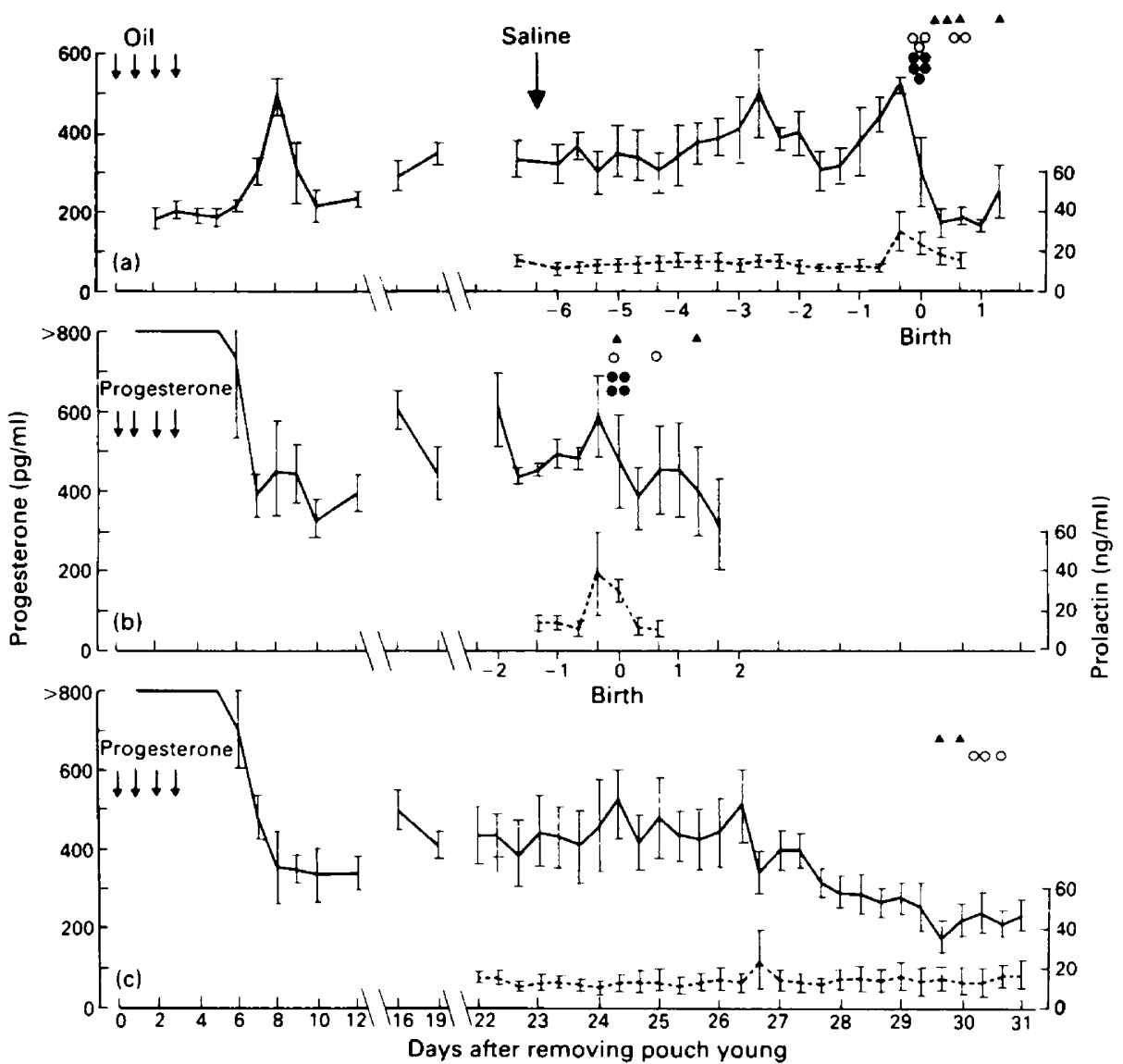

Fig. 1. Effect of fetal development on the concentrations (mean \pm s.e.m.) of progesterone $(-)$ and prolactin (-- ) in plasma and the time of parturition $(\bullet)$, oestrus $(O)$ and the LH pulse (A) in individual tammars. (a) Control treated pregnant tammars, Group 1; (b) pregnant tammars treated with progesterone during Days $0-3$ to induce early reactivation of the blastocyst and advance the pre-partum pulse of prolactin, Group 2; (c) non-pregnant tammars treated with progesterone during Days 0-3, Group 5. For (a) the values for progesterone to Day 12 are synchronized to the modal day of the early pulses of progesterone, and for (a) and (b), the later values for progesterone and prolactin are synchronized to the mean time of parturition for each group.

As in Group 2, injections of progesterone during Days 0-3 (Group 5) caused very high levels in the circulation for the first 4-5 days (Fig. Ic) and hence would have obscured any early endogenous pulse of progesterone from the reactivated CL. However, all 5 animals reactivated although in 3 the process was delayed so that ovulation had not occurred by Day 32 at autopsy. Two animals had prolactin pulses on Day 27 and 29 respectively but these were not associated with any change in plasma progesterone. The time of the fall in plasma progesterone was not significantly earlier than in Group 4 and 3 animals showed oestrus and 2 had LH pulses at times that were not significantly different from the control Group 4 (Table 2). This is in marked contrast to the effects of exogenous progesterone on the pregnant cycle seen in Group 2 (compare Figs $1 \mathrm{~b}$ and $1 \mathrm{c}$ ).

All 5 animals in Group 6 reactivated and displayed a progesterone pulse after $6 \cdot 0 \pm 0 \cdot 3$ days. This was significantly earlier than in Group $4(P<0.01$, Table 2$)$, despite both groups having received the same treatment until Day 26. The injection of prolactin on Day 26 was followed in all 5 


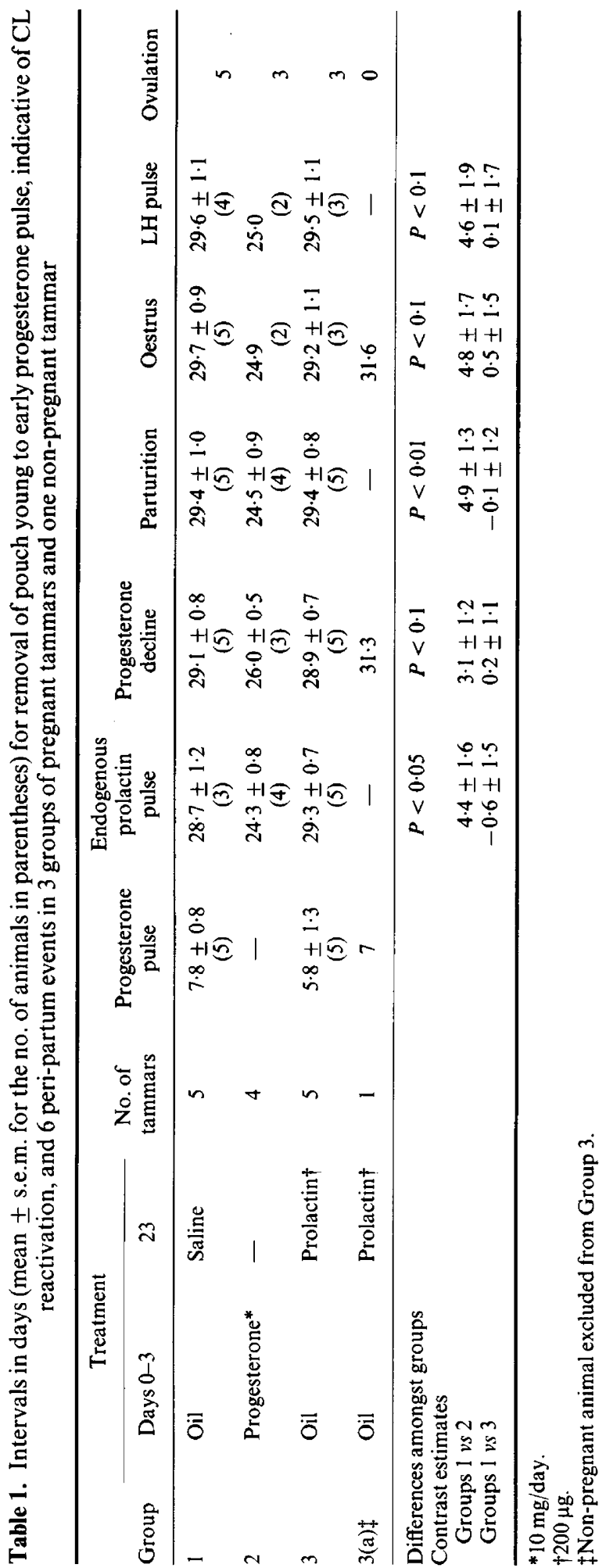




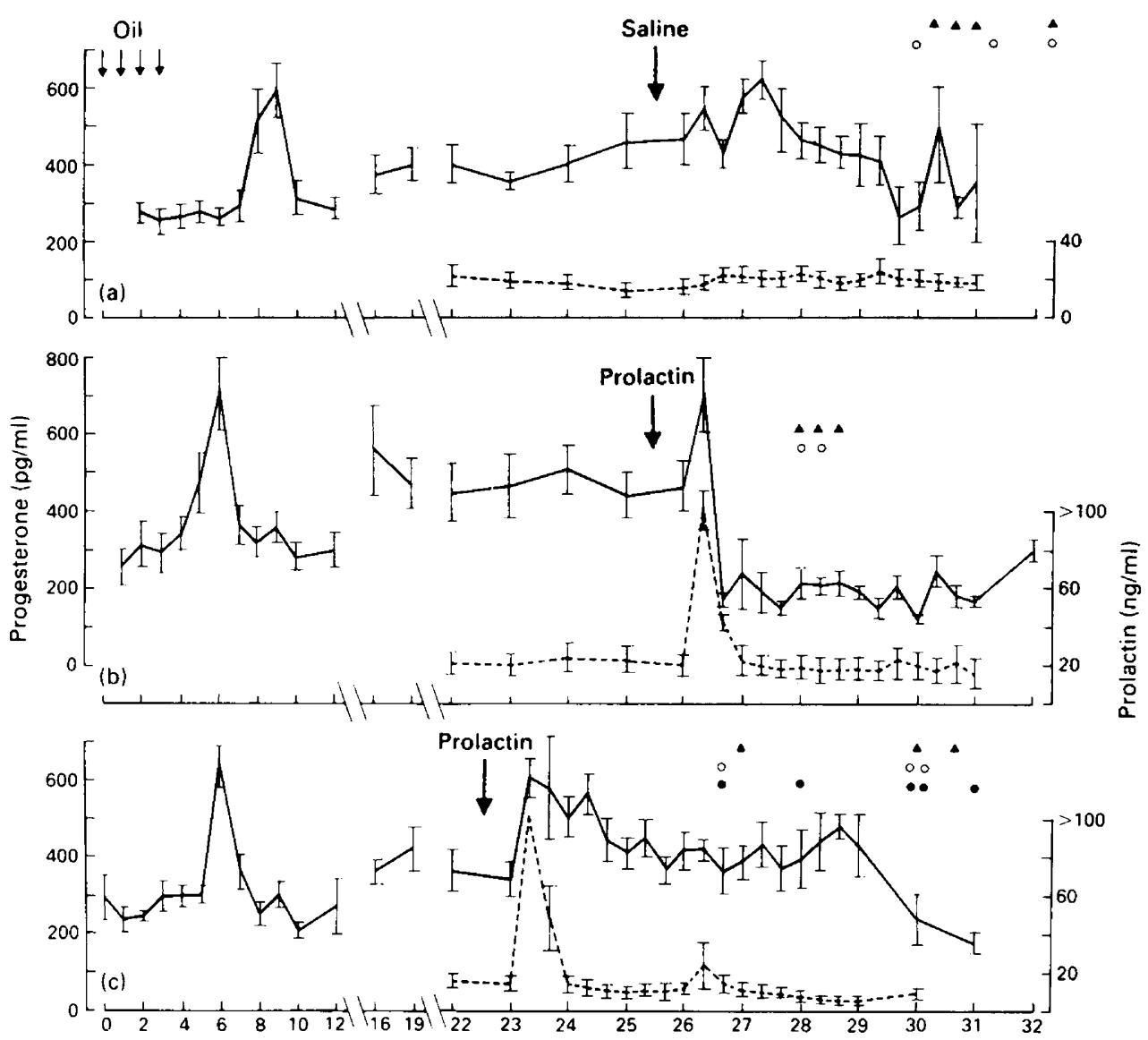

Fig. 2. Effect of an exogenous pulse of prolactin on concentration (mean \pm s.e.m.) of progesterone (-) and prolactin (---), and on the time of parturition $(\bullet)$, oestrus $(O)$ and the LH pulse ( $\Delta$ ) in individual tammars. (a) Control treated non-pregnant tammars, Group 4; (b) nonpregnant tammars injected with $200 \mu \mathrm{g}$ prolactin on Day 26, Group 6; (c) pregnant tammars injected with $200 \mu \mathrm{g}$ prolactin on Day 23, Group 3. Values for progesterone to Day 12 have been synchronized to the modal day of the early pulse of progesterone.

tammars by a very large rise in the level of circulating prolactin $4 \mathrm{~h}$ later, which had disappeared $20 \mathrm{~h}$ after injection (Fig. 2b). Apart from this brief pulse the level of prolactin in all animals remained below $20 \mathrm{ng} / \mathrm{ml}$ throughout the sampling period. Coincident with the peak concentration of prolactin in the first sample after injection, the progesterone concentration increased $13 \%$ to $82 \%$, as in Group 3. However, in the next sample, $12 \mathrm{~h}$ after injection of prolactin, it had fallen to basal levels, where it remained in all subsequent samples of the 5 animals (Fig. $2 b$ ), so that the interval from the early pulse of progesterone to the fall in progesterone was $20 \cdot 7 \pm 0 \cdot 3$ days. This decline in progesterone was more abrupt (Fig. 2b) and significantly $(P<0.001)$ earlier than the decline in the other non-pregnant tammars of control Group 4 (Table 2). When allowance was made for the earlier time to the progesterone pulse in Group 6 compared to Group 4, the residual difference between the intervals from the early progesterone pulse to the fall in progesterone in the two groups was still significant $\left(t_{8}=2 \cdot 85, P<0.02\right)$.

Of the 5 tammars, 2 showed oestrus on Day 28 and these and one other had pulses of LH at this time and 4 of the 5 had ovulated by Day 32 (Table 2; Fig. 2b). 


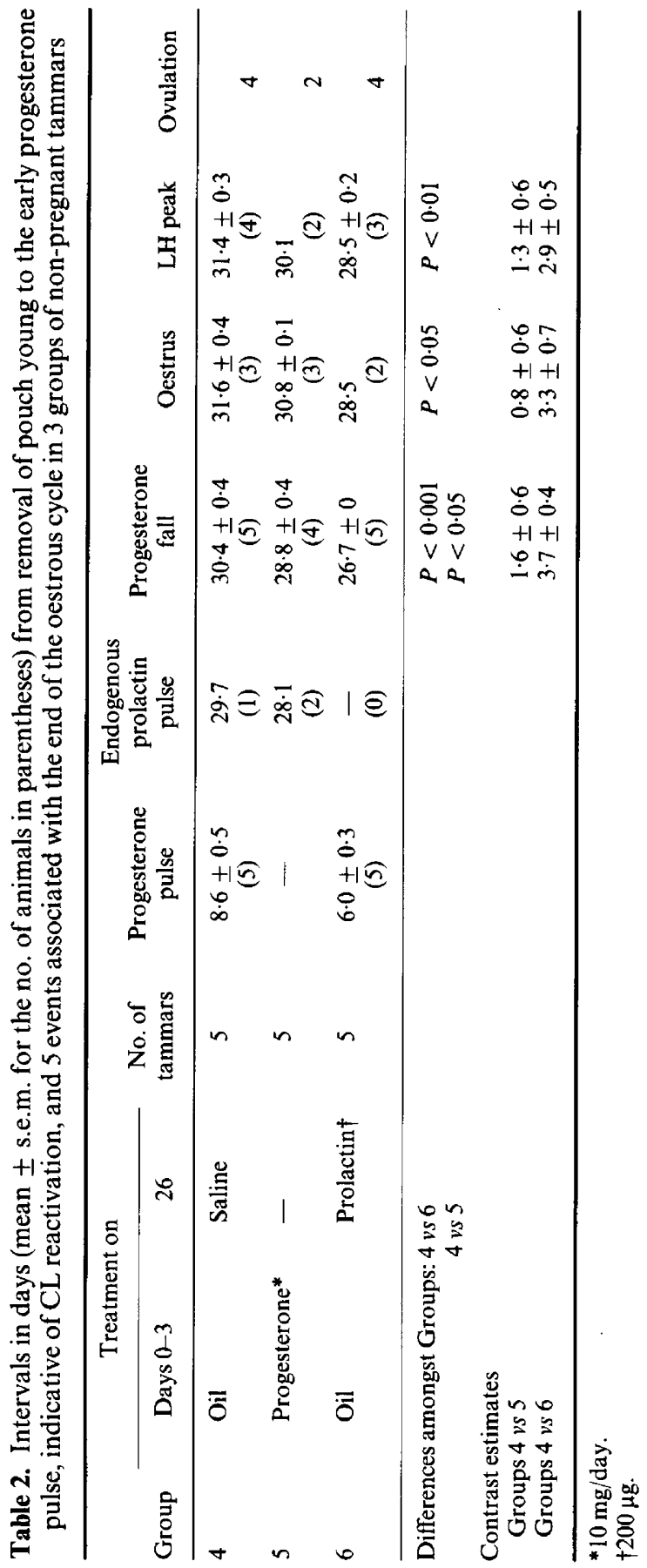


The single non-pregnant animal in Group 3 that received an injection of prolactin on Day 23 did not show the sharp decline in progesterone concentration observed in Group 6 but a gradual decline beginning on Day 30, as in the control non-pregnant animals of Group 4.

\section{Discussion}

The results of Exp. 1 support the hypothesis that the prolactin pulse at the end of the cycle in the tammar is associated with parturition; a pulse was detected in 12 out of 14 animals that gave birth and, in those in which parturition was advanced experimentally, so was the time of the prolactin pulse. However, the occurrence of a prolactin pulse in 3 out of the 16 non-pregnant tammars in this study and 2 out of 26 in previous studies indicates that the prolactin probably originates in the mother rather than the conceptus. This gains support from the evidence that parturition is prevented by hypophysectomy (Hearn, 1974) but not by immunization against GnRH (Short et al., 1985). While the fetus may play a role in provoking a prolactin pulse at the end of pregnancy it is evident that a prolactin pulse may also, occasionally, occur spontaneously in non-pregnant tammars at this stage. As Clark (1968) found in red kangaroos, treatment with progesterone can advance embryo development but does not affect CL development, which was initiated in the usual way when the pouch young were removed. Although the resultant delivery of young 4-5 days earlier than in controls (Group 1) advanced the prolactin pulse to the same extent, the CL was not so clearly affected, nor were the events associated with post-partum oestrus and ovulation.

The results of Exp. 2, designed to mimic in non-pregnant tammars the pre-partum pulse of prolactin, support the second hypothesis, that prolactin is luteolytic and probably is responsible for the very rapid decline in progesterone that occurs between Day 26 and 29 in pregnant tammars; all the non-pregnant females treated with exogenous prolactin on Day 26 had progesterone profiles like pregnant females. However, exposure of pregnant females to the same dose of prolactin on Day 23 did not have a luteolytic effect or affect the timing of parturition. Since the one nonpregnant animal in this group, treated on Day 23, likewise showed no sudden fall in progesterone, we may conclude that the different responses are not due to the pregnant state of the animals but to the stage of the reproductive cycle when prolactin was injected. Similarly, in the Group 2 females, although the prolactin pulse was advanced by several days in concordance with the early birth of the young, the progesterone concentrations in 2 out of 4 animals were not reduced at the same time. The alternative hypothesis, suggested by Lewis et al. (1986), that the peri-partum pulse of prostaglandin is the agent of luteolysis remains to be tested. Until then the relationship between this and the pre-partum pulse of prolactin and the respective roles of each in luteolysis cannot be resolved.

The results support the earlier conclusion of Merchant (1979) and Tyndale-Biscoe et al. (1983) that the fetus is involved in the shortened life of the CL and the earlier time to oestrus after parturition than after a non-pregnant cycle. The agent of the shortening has been shown to be a transient pulse of prolactin, which precedes parturition and directly or indirectly causes luteolysis of the $\mathrm{CL}$ of pregnancy. This conclusion still leaves unresolved the question of how the fetus provokes the release of prolactin, presumably from the maternal pituitary.

We thank Dr Peter Diggle, Division of Mathematics \& Statistics, CSIRO for the statistical analyses in this paper; and Brian Green, Ray Leckie, Jim Merchant and Keith Newgrain for their help with collecting the blood samples.

\section{References}

Clark, M.J. (1968) Termination of embryonic diapause in the red kangaroo, Megaleia rufa, by injection of progesterone or oestrogen. J. Reprod. Fert. 15, 347-355. 
Gemmell, R.T. (1985) The effect of prostaglandin F2a analog on the plasma concentration of progesterone in the bandicoot, Isoodon macrourus (Marsupialia: Peramelidae), during lactation. Gen. comp. Endocr. 57, 405-410.

Harder, J.D., Hinds, L.A., Horn, C.A. \& Tyndale-Biscoe, C.H. (1985) Effects of removal in late pregnancy of the corpus luteum, Graafian follicle or ovaries on plasma progesterone, oestradiol, LH, parturition and postpartum oestrus in the tammar wallaby, Macropus eugenii. J. Reprod. Fert. 75, 449-459.

Hearn, J.P. (1974) The pituitary gland and implantation in the tammar wallaby, Macropus eugenii. J. Reprod. Fert. 39, 235-241.

Hinds, L.A. \& Tyndale-Biscoe, C.H. (1982a) Plasma progesterone levels in the pregnant and non-pregnant tammar, Macropus eugenii. J. Endocr. 93, 99-107.

Hinds, L.A. \& Tyndale-Biscoe, C.H. (1982b) Prolactin in the marsupial, Macropus eugenii, during the estrous cycle, pregnancy and lactation. Biol. Reprod. 26, 391-398.

Hinds, L.A. \& Tyndale-Biscoe, C.H. (1985) Seasonal and circadian patterns of circulating prolactin during lactation and seasonal quiescence in the tammar, Macropus eugenii. J. Reprod. Fert. 74, 173-183.

Kirsch, J.A.W. \& Poole, W.E. (1972) Taxonomy and distribution of the grey kangaroos, Macropus giganteus Shaw and Macropus fuliginosus (Desmarest), and their subspecies (Marsupialia: Macropodidae). Aust. J. Zool. 20, 315-339.

Lewis, P.R., Fletcher, T.P. \& Renfree, M.B. (1986) Prostaglandin in the peripheral plasma of tammar wallabies during parturition. J. Endocr. 11, 103-109.

Merchant, J.C. (1979) The effect of pregnancy on the interval between one oestrus and the next in the tammar wallaby, Macropus eugenii. J. Reprod. Fert. 56, $459-463$.
Moore, G.P.M. (1978) Embryonic diapause in the marsupial Macropus eugenii. Stimulation of nuclear RNA polymerase activity in the blastocyst during resumption of development. J. Cell Physiol. 94, 31-36.

Nicholas, K.R. \& Tyndale-Biscoe, C.H. (1985) Prolactindependent accumulation of alpha-lactalbumin in mammary gland explants from the pregnant tammar (Macropus eugenii). J. Endocr. 106, 337-342.

Poole, W.E. (1975) Reproduction in the two species of grey kangaroos, Macropus giganteus Shaw and $M$. fuliginosus (Desmarest). II Gestation, parturition and pouch life. Aust. J. Zool. 23, 333-353.

Renfree, M.B. \& Tyndale-Biscoe, C.H. (1973) Intrauterine development after diapause in the marsupial Macropus eugenii. Devl Biol. 32, 28-40.

Sernia, C., Hinds, L.A. \& Tyndale-Biscoe, C.H. (1980) Progesterone metabolism during embryonic diapause in the tammar wallaby, Macropus eugenii. J. Reprod. Fert. 60, 139-147.

Short, R.V., Flint, A.P.F. \& Renfree, M.B. (1985) Influence of passive immunization against GnRH on pregnancy and parturition in the tammar wallaby, Macropus eugenii. J. Reprod. Fert. 75, 567-575.

Sutherland, R.L., Evans, S.M. \& Tyndale-Biscoe, C.H. (1980) Macropodid marsupial luteinising hormone: validation of assay procedures and changes in concentrations in plasma during the oestrous cycle in the female tammar wallaby (Macropus eugenii) $J$. Endocr. 86, 1-12.

Tyndale-Biscoe, C.H., Hinds, L.A., Horn, C.A. \& Jenkins, G. (1983) Hormonal changes at oestrus, parturition and post-partum oestrus in the tammar wallaby (Macropus eugenii). J. Endocr. 96, 155-161.

Ward, K.L. \& Renfree, M.B. (1984) Effects of progesterone on parturition in the tammar, Macropus eugenii. J. Reprod. Fert. 72, 21-28.

Received 10 February 1987 